\title{
Do Quarantine Experiences and Attitudes Towards COVID-19 Affect the Distribution of Mental Health in China? A Quantile Regression Analysis
}

\author{
Haiyang Lu ${ }^{1}$ (D) Peng $\mathrm{Nie}^{2}$ (D) $\cdot$ Long Qian ${ }^{3}$
}

Received: 25 April 2020 / Accepted: 8 June 2020 /Published online: 29 June 2020

(C) The International Society for Quality-of-Life Studies (ISQOLS) and Springer Nature B.V. 2020

\begin{abstract}
While quarantine has become a widely used control strategy during the outbreak of the 2019 novel coronavirus disease (COVID-19), empirical research on whether and to what extent quarantine and attitudes towards COVID-19 affect mental health is scant. Using a cross-sectional online survey, this paper is the first from the Chinese outbreak to investigate how quarantine experiences and attitudes towards COVID-19 are related to mental health, and how these relationships change across the distribution of mental health scores. Using quantile regression analysis, we found that home self-quarantine is associated with a decrease in depression and an increase in happiness, while community-level quarantine is associated with decreased happiness, especially for those in the lower happiness quantile. We also found that favorable attitudes towards COVID-19 regarding the credibility of real-time updates and confidence in the epidemic control are associated with lower levels of depression and higher levels of happiness. These effects are stronger in the upper quantile of depression and the median quantile of happiness.
\end{abstract}

Keywords Quarantine·Attitudes · Quantile regression · Mental health

Haiyang Lu

luhy@swufe.edu.cn

Peng Nie

Peng_Nie@uni-hohenheim.de

Long Qian

qianlongy101@126.com

1 The West Center for Economics Research, Southwestern University of Finance and Economics, Chengdu 611130, China

2 School of Economics and Finance, Xi'an Jiaotong University, Xi'an 710061, China

3 Institute of Food Economics, Nanjing University of Finance \& Economics, Nanjing 210003, China 


\section{Introduction}

Since December 2019, the outbreak of a novel coronavirus disease (COVID-19), which was first reported in Wuhan, Hubei province, China, has become a global concern. By May 24, 2020, there were 84,525 confirmed cases of COVID-19 in China including 4645 people who had died due to the infection. Globally, the number of COVID-19 cases has surged, with 5,206,614 confirmed cases in more than two hundred countries/ areas (WHO 2020). Public health efforts to curb the rapid transmission of COVID-19 have led to infection control measures dominating hospital procedures and policies in China. All levels of Chinese government have implemented a range of containment measures, including early detection and isolation of suspected and confirmed cases, establishment of Fangcang shelter hospitals (Chen et al. 2020), travel restrictions, dissemination of diagnostic kit, and widespread quarantines (Xiang et al. 2020).

The outbreak of COVID-19 has motivated research on the psychological challenges that this epidemic poses to health professionals, patients, and the public. As highlighted by Jalloh et al. (2018), individuals face mental health problems such as anxiety, stress, depression, insomnia, and anger in the fight against epidemics such as SARS and Ebola. Although some recent studies, including Kang et al. (2020) and Liu et al. (2020), have reported on the psychological impact of COVID-19, published reports are still limited. In this paper, we examine the effect of quarantine experiences and attitudes towards COVID-19 on mental health among adults in China and how this effect changes across the distribution of mental health scores.

Our work complements the existing literature on the psychological impact of disease outbreaks in the following ways: First, unlike most previous studies focusing on negative domains of mental health such as psychiatric morbidity (Chong et al. 2004) and psychological distress (Lee et al. 2018), we measure both positive and negative metrics of mental health, depressive symptoms and happiness. This combination may allow researchers to gain a fuller picture of the psychological impacts of COVID-19 including how COVID-19 impacts quality of life (QOL) in human beings (Shek 2014). Second, we use a quantile regression approach to analyze the potential heterogeneity in the relationship of mental health to quarantine experiences and attitudes about COVID-19 across the distribution of mental health measures. Because we examine these associations in China, where the disease first emerged and is currently under effective control, our findings will have important implications for other countries affected by the pandemic. This is especially the case given that previous research has focused on the psychological consequences of epidemics in the context of developed countries (e.g., Locke et al. 2019; Sprang and Silman 2013), while research from developing and emerging settings has been limited. As Shek (2014) and Ma et al. (2019) have emphasized, research contributions from different cultural contexts can help to chart a global contour of applied QOL.

\section{Prior Literature}

\section{Quarantine and Psychological Outcomes}

In the health literature, "quarantine" is commonly defined as the separation or restriction of the activities of individuals who may have been exposed to infectious diseases 
to reduce their risk of infecting others (Brooks et al. 2020). Conceptually, "quarantine" is often used interchangeably with "isolation" and both terms are used in the context of infection prevention. However, there is also a clear distinction between the two terms: the former applies to individuals who are asymptomatic or are not yet ill, while the latter is for patients who are symptomatic or known to have a contagious disease (Barbisch et al. 2015).

Although quarantine is to protect individuals' health from infectious diseases, it has been widely regarded as an unpleasant experience that may trigger various psychological problems such as depression, anxiety, fear, loneliness, resentment, and confusion (Lin et al. 2010). For instance, using data from a survey in South Korea during the Middle East Respiratory Syndrome (MERS) epidemic, Jeong et al. (2016) found that during quarantine, approximately $16.6 \%$ and $7.6 \%$ of respondents reported anger and anxiety symptoms, respectively. Sprang and Silman (2013) found that diseasecontainment measures such as quarantine and isolation have a detrimental impact on children and their parents, manifested in symptoms of post-traumatic stress disorder (PTSD).

There are several reasons why quarantine is likely to have a detrimental impact on mental health. First, those who are quarantined may face difficulties getting food and other daily necessities (DiGiovanni et al. 2004). Lack of access to basic supplies could give rise to feelings of tension, frustration, and anxiety (Maynard et al. 2019). Second, quarantined individuals are likely to be discriminated against and ostracized by their neighbors and other groups, and a feeling of stigmatization is common among people with quarantine experiences (Karamouzian and Hategekimana 2015). Such stigmatization may exacerbate stress and mental health deterioration for people in quarantine (Robertson et al. 2004). Moreover, quarantine may be accompanied by other psychologically damaging factors including financial loss, inadequate access to information, and boredom (Brooks et al. 2020). Although there is some evidence that quarantine experiences are negatively associated with psychological outcomes (e.g., Reynolds et al. 2008; Taylor et al. 2008), quarantine may also have beneficial psychological impacts because it can effectively reduce an individual's risk of being infected, thereby alleviating the infectious pressure on them (Locke et al. 2019). A key aim of the current study is to examine this possibility.

\section{The Role of Attitudes in Mental Health}

The role of attitudes in predicting emotional functioning has been extensively documented in the mental health literature (e.g., Ayers et al. 2010; Iyer and Muncy 2016). Using data from a 9-year follow-up survey, Halvorsen et al. (2010) found that dysfunctional attitudes are closely related to depression severity. Aghababaei et al. (2016), using a sample of college students in Iran, found that both religious and scientific attitudes are positively associated with life satisfaction, happiness, and selfesteem.

Closer to our interest is a small but growing body of research on the relationship between attitudes towards disease and mental health. One branch of the literature looks at the impact of attitude towards disease severity on the mental health of patients (e.g., Moss Morris et al. 1996; Zhang et al. 2016). Using a sample of heart failure patients from Ireland, Morgan et al. (2014) found that perceptions of illness were correlated 
with mental health, and suggested that control-related attitudes could have a protective role in health-related outcomes. This finding is in line with the work by Callus et al. (2014), who showed that attitudes about the severity of cardiac disease are associated with the patients' pre-operative psychological state. In addition to attitudes about disease itself, Boyes et al. (2006) found that a positive attitude towards real-time feedback of health information improves patients' symptom control, although it has no significant impact on their mental health.

In sum, favorable attitudes predict a wide range of successful adaptations to adverse circumstances and can have protective effects against illness, disability, and depression (Kato et al. 2016). As reported by Shallcross et al. (2010), embracing negative experiences may protect individuals from negative emotions and prevent depression. For example, a systematic review by Ayers et al. (2010) indicates that women who hold a more negative attitude towards menopause report more mental health-related symptoms during the menopause transition.

\section{Data and Methods}

\section{Study Design and Sample}

The need to prevent continued transmission of COVID-19 has precluded the use of traditional face-to-face surveys. Instead, given the wide availability of the mobile Internet in China, online surveys are safer and more feasible. As such, we conducted an anonymous, mobile Internet-based, cross-sectional survey entitled "Social Attitudes and Psychological Health during the COVID-19 Pandemic" between March 6, 2020, and March 12, 2020. This cross-sectional study was conducted in accordance with the STROBE (Strengthening the Reporting of Observational Studies in Epidemiology) statement. The online questionnaire was designed using WenJuan, a popular Internet survey platform in China (https://www.wenjuan.com/), and was completed voluntarily after clicking on a survey solicitation link. Using a snowballing sampling technique, our survey collected a total of 1951 respondents from all 31 mainland provinces/municipalities/autonomous regions. In this paper, we focus on respondents aged between 16 and 65 and exclude from the sample those who lacked responses for core variables (including depressive symptoms, happiness, quarantine experience, and attitudes towards COVID-19). As a result, 1849 observations remain after data cleaning.

\section{Outcome Variables}

In order to contribute to a multidimensional understanding of how quarantine impacts mental health, we measured both depressive symptoms and happiness. We measured depressive symptoms using a short form of the Center for Epidemiological Studies Depression (CES-D; Radloff (1977)) scale (CES-D-9) which has been developed and tested for use with Chinese people in health and well-being studies (e.g., Cheung et al. 2007; Xu et al. 2019). Shrout and Yager (1989) and Boey (1999) found that the sensitivity and specificity of the CES-D are not affected by using the shorter version. 
The CES-D-9 used in this paper measures cognitive, emotional, and motivational aspects of depression, as discussed by Shek (1990). On a 5-point scale from " 1 = never or rarely" to " $5=$ most or all the time," respondents indicated how often they had experienced the following during the past week: (i) loss of appetite, (ii) emotional upset, (iii) hopelessness for the future, (iv) a feeling that life is meaningless, (v) poor sleep, (vi) inability to concentrate, (vii) sadness, (viii) fear, and (ix) difficulty doing daily activities. A composite indicator for depressive symptoms was then created by summing all responses, with a total score ranging from 9 to 45 , where higher scores indicate more depressive symptoms. The CES-D-9 has been shown to have a high reliability in terms of internal consistency (Cronbach's alpha $=0.91$ ).

In order to measure individual happiness, we also included a question following Arampatzi et al. (2018), "All things considered, how happy are you with your life as a whole?" (responded to on a 10-point scale ranging from " $1=$ totally unhappy" to " $10=$ totally happy"). As shown in Figs. 1 and 2, the distribution of depression scores is skewed to the left with a long right tail, while the distribution of happiness is skewed slightly to the right.

\section{Key Independent Variables}

We employed three metrics to measure attitudes towards COVID-19. First, severity perception, referring to an individual's perception of COVID-19 severity, is coded as 1 if the respondent believes that the negative impact of the pandemic on him/her will last for at least 3 months, and 0 otherwise. Second, credibility of real-time data captures whether an individual has a very high level of trust in the real-time updates of COVID19 cases $(1=$ yes, $0=$ otherwise). Third, pandemic control reflects an individual's confidence in the control of COVID-19 ( $1=$ very or fairly confident, $0=$ otherwise).

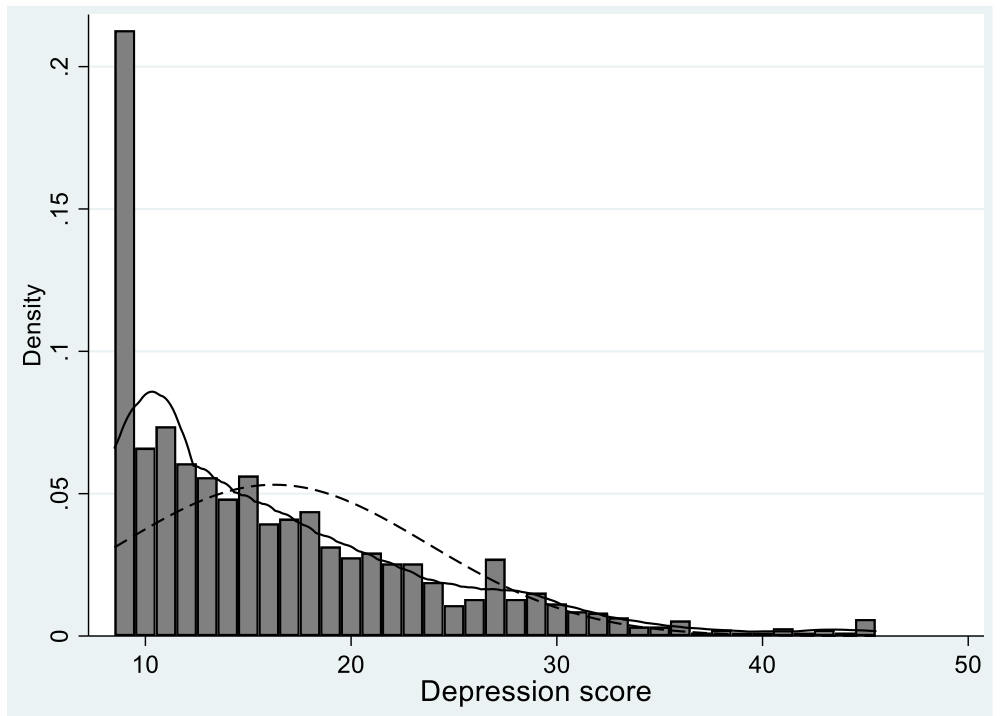

Fig. 1 Histogram of depressive symptoms, overlaid with kernel density (solid) and normal density (dashed) plots 


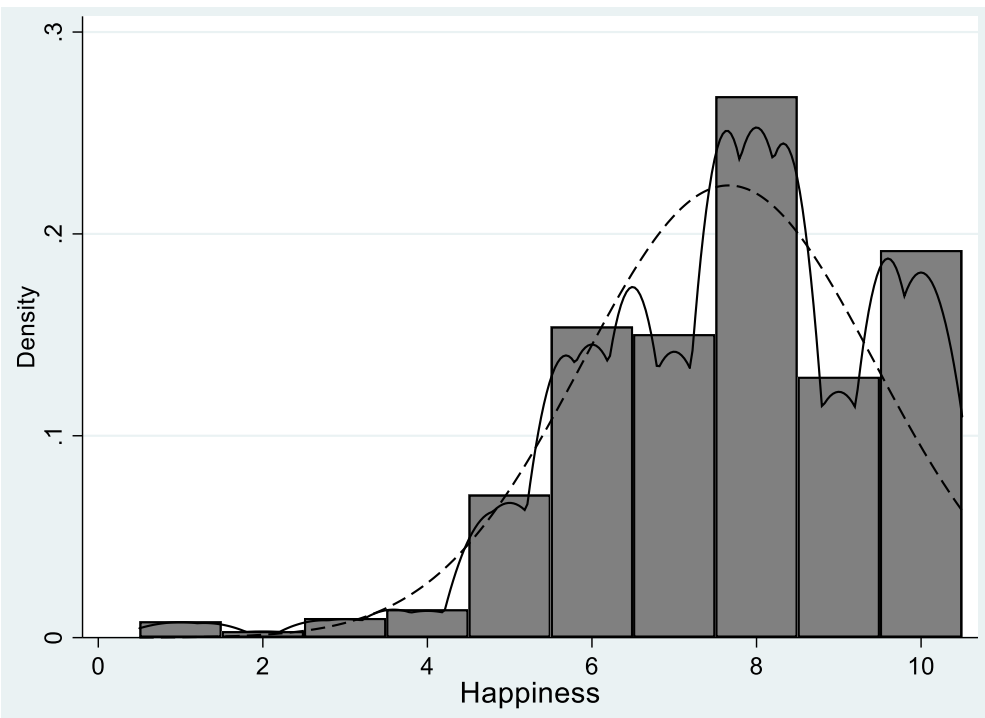

Fig. 2 Histogram of happiness, overlaid with kernel density (solid) and normal density (dashed) plots

Regarding quarantine experiences, we measured aspects of both micro- and macrolevels of quarantine. The former is home-based quarantine, captured by the question "How often did you go out during the COVID 19 outbreak?" and measured on a 4point scale $(1=$ never, $2=$ once or twice a week, $3=$ three or four times a week, and $4=$ everyday). For use in our analyses, we recoded responses to a dichotomous measure, with 1 if the respondent never went out, and 0 otherwise. The latter, labeled communitylevel quarantine, was also measured with a binary variable that equals 1 if the community/village where the respondent resides is blocked, 0 otherwise. Finally, since quarantine was also used as a control measure during the 2003 SARS outbreak in China, we assessed the effect of previous quarantine experience on current mental health. This variable was measured by asking the respondent if he or she experienced home quarantine during the 2003 SARS outbreak ( $1=$ yes, $0=$ otherwise).

\section{Regression Covariates}

For regression analyses, we included a set of covariates that are plausibly linked to mental health. Based on previous work (e.g., Binder and Coad 2011; Zhang et al. 2015), we controlled for gender $(1=$ male, $0=$ female $)$, age, self-reported health $(1=$ good, $0=$ other), household registration type (hukou) $(1=$ rural, $0=$ urban), education attainment $(1=$ primary school, 2 = junior middle school, 3 = senior middle school, $4=$ college or above), household economic status ( $1=$ poor family, $0=$ other $)$, marital status ( $1=$ married, $0=$ other $)$, religiosity $(1=$ religious believer, $0=$ other $)$, COVID- 19 confirmed cases among relatives/friends $(1=$ yes, $0=$ no), food/water shortage $(1=$ yes, $0=$ no), family contacts $(1=$ close contact with family members, $0=$ other $)$, perceived fairness $(1=$ high, $0=$ other $)$, and generalized trust $(1=$ high, $0=$ other $)$. Finally, provincial dummies were included to capture unobserved fixed effects at the provincial level. 


\section{Analysis Strategy}

The predictors of mental health have been found to vary across different parts of the mental health distribution. For example, Binder and Coad (2011) found that the determinants of happiness vary across different quantiles of the happiness distribution. In our work, due to the non-normal distribution of dependent variables, the impact of quarantine and attitudinal factors may differ across the distributions of depressive symptoms and perceived happiness. As such, in addition to ordinary least squares (OLS) method, we also report estimates from quantile regressions (QR). The QR method, developed by Koenker and Bassett (1978), allows us to investigate how the effect of predictors changes across the distribution of mental health measures.

The quantile estimators are obtained by solving the following optimization problem:

$$
\min _{\beta \in R^{k}}\left[\sum_{i \in\left\{i: y_{i} \geq x_{i}^{\prime} \beta\right\}} \theta\left|y_{i}-x_{i}^{\prime} \beta\right|+\sum_{i \in\left\{i: y_{i}<x_{i}^{\prime} \beta\right\}}(1-\theta)\left|y_{i}-x_{i}^{\prime} \beta\right|\right]
$$

For the $\theta$ th quantile $(0<\theta<1), y_{i}$ is psychological outcome (depressive symptoms or perceived happiness), and $x_{i}$ is a vector of explanatory variables including quarantine experiences, attitudes towards COVID-19, and other covariates.

\section{Results}

\section{Descriptive Statistics and Pairwise Correlations}

Table 1 provides an overview of the descriptive statistics. Female respondents accounted for $63 \%$ of our sample. The average age of the respondents was about 31 years old, and females were younger on average than males ( 30 versus $32, p<0.01$ ). Females were more likely than males to hold favorable attitudes towards COVID-19 as indicated by their severity perception $(0.34$ versus $0.43, p<0.01)$ and confidence in pandemic control $(0.92$ versus $0.90, p<0.05)$ responses. Interestingly, although males had more quarantine experiences than females during the 2003 SARS, females were more likely to be quarantined at home than males during the COVID-19 pandemic.

Although the gender difference in mean depression was not significant, the mean happiness score for females was significantly higher than that for males (7.78 versus $7.47, p<0.01)$. To get a more complete picture of mental health during the COVID-19 pandemic, we also investigated several other types of emotions. As illustrated in Fig. 3, more than $58 \%$ of respondents reported anxiety, and $35 \%, 17.1 \%$, and $16.6 \%$ reported panic, anger, and helplessness, respectively. Fewer participants reported numbness (9.6\%) and desperation (3.7\%). Finally, we found gender differences in the reported symptoms, with females more likely to report anxiety and panic, and males more likely to report feeling depressed and coerced.

Table 2 presents pairwise correlations between our main variables of interest. We found a significant negative correlation between depressive symptoms and happiness $(r=-0.32$, $p<0.01$ ), and all three attitudinal metrics were significantly correlated with depressive 
Table 1 Descriptive statistics

\begin{tabular}{|c|c|c|c|c|c|c|c|c|}
\hline Variables & Mean & Min & $\operatorname{Max}$ & 25 th & 50 th & 75th & Females & Males \\
\hline Depressive symptoms & $16.26(7.51)$ & 9 & 45 & 10 & 14 & 20 & 16.26 & 16.24 \\
\hline Happiness & $7.66(1.78)$ & 1 & 10 & 6 & 8 & 9 & 7.78 & $7.47 * * *$ \\
\hline Severity perception & $0.37(0.48)$ & 0 & 1 & 0 & 0 & 1 & 0.34 & $0.43^{* * *} *$ \\
\hline Credibility of real-time data & $0.11(0.31)$ & 0 & 1 & 0 & 0 & 0 & 0.11 & 0.12 \\
\hline Pandemic control & $0.91(0.28)$ & 0 & 1 & 1 & 1 & 1 & 0.92 & $0.90 * *$ \\
\hline SARS quarantine experience & $0.28(0.45)$ & 0 & 1 & 0 & 0 & 1 & 0.26 & $0.33^{* * * *}$ \\
\hline Community-level quarantine & $0.93(0.26)$ & 0 & 1 & 1 & 1 & 1 & 0.93 & 0.92 \\
\hline Home quarantine & $0.46(0.50)$ & 0 & 1 & 0 & 0 & 1 & 0.50 & $0.39 * * *$ \\
\hline Gender & $0.37(0.48)$ & 0 & 1 & 0 & 0 & 1 & - & - \\
\hline Age & $30.62(9.44)$ & 16 & 65 & 24 & 28 & 36 & 29.76 & $32.07 * * *$ \\
\hline Self-reported health & $0.69(0.46)$ & 0 & 1 & 0 & 1 & 1 & 0.71 & $0.67 * *$ \\
\hline Rural hukou & $0.38(0.48)$ & 0 & 1 & 0 & 0 & 1 & 0.38 & 0.37 \\
\hline Primary school & $0.01(0.10)$ & 0 & 1 & 0 & 0 & 0 & 0.01 & 0.01 \\
\hline Junior middle school & $0.06(0.24)$ & 0 & 1 & 0 & 0 & 0 & 0.06 & 0.06 \\
\hline Senior middle school & $0.10(0.30)$ & 0 & 1 & 0 & 0 & 0 & 0.10 & 0.10 \\
\hline College or above & $0.83(0.37)$ & 0 & 1 & 1 & 1 & 1 & 0.83 & 0.83 \\
\hline Poor family & $0.17(0.38)$ & 0 & 1 & 0 & 0 & 0 & 0.15 & $0.20 * * *$ \\
\hline Married & $0.43(0.50)$ & 0 & 1 & 0 & 0 & 1 & 0.39 & $0.49 * * *$ \\
\hline Religious believer & $0.08(0.28)$ & 0 & 1 & 0 & 0 & 0 & 0.08 & 0.08 \\
\hline COVID-19 cases & $0.02(0.12)$ & 0 & 1 & 0 & 0 & 0 & 0.01 & 0.02 \\
\hline Food/water shortage & $0.10(0.29)$ & 0 & 1 & 0 & 0 & 0 & 0.10 & 0.10 \\
\hline Family contacts & $0.63(0.48)$ & 0 & 1 & 0 & 1 & 1 & 0.64 & $0.60 * *$ \\
\hline Perceived fairness & $0.41(0.49)$ & 0 & 1 & 0 & 0 & 1 & 0.41 & 0.41 \\
\hline Generalized trust & $0.50(0.50)$ & 0 & 1 & 0 & 1 & 1 & 0.51 & 0.48 \\
\hline
\end{tabular}

$* p<0.1, * * p<0.05, * * * p<0.01$. Significance levels are obtained from $t$ tests. Standard deviations are shown in parentheses

symptoms and happiness. Severity perception was positively correlated with depressive symptoms $(r=0.17, p<0.01)$ and negatively correlated with happiness $(r=-0.11$, $p<0.01)$. Similarly, depressive symptoms were negatively correlated with both credibility of real-time data $(r=-0.08, p<0.01)$ and pandemic control $(r=-0.17, p<0.01)$, while happiness was positively correlated with credibility of real-time data $(r=0.12, p<0.01)$ and pandemic control $(r=0.18, p<0.01)$. Regarding quarantine measures, SARS quarantine experience was positively correlated with depressive symptoms $(r=0.06, p<0.05)$, while home quarantine was positively correlated with happiness $(r=0.05, p<0.05)$. We next examined these correlational relationships in the context of multivariate regression, controlling for demographic and socioeconomic characteristics.

\section{Multivariate Regression Analysis}

Table 3 shows estimation results for the impact of quarantine and attitudes towards COVID-19 on depressive symptoms. We first examined the correlates of depressive 


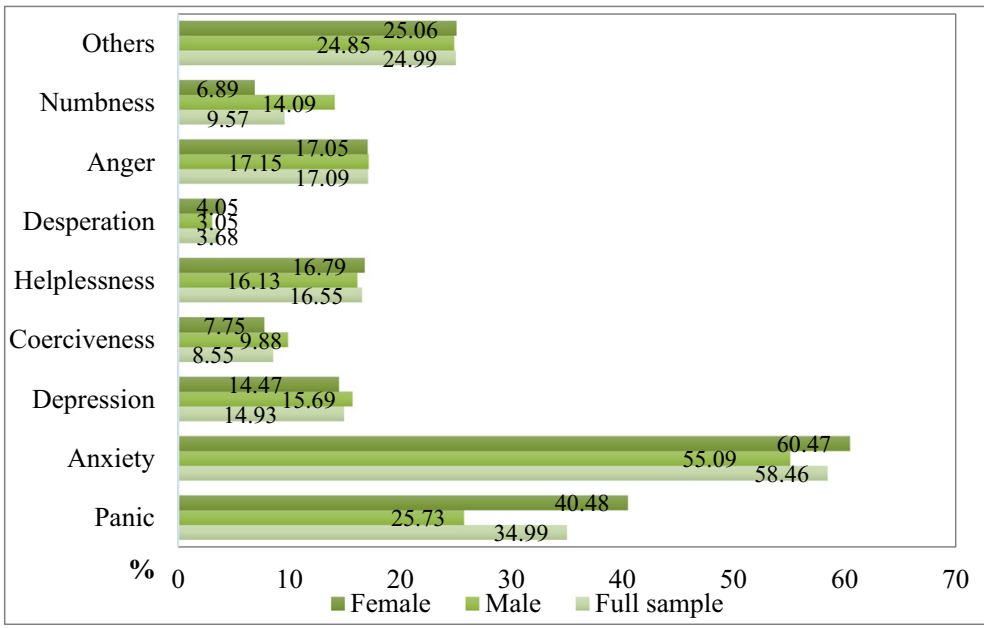

Fig. 3 The prevalence of negative emotions

symptoms based on the OLS regression (column 1). After controlling for other covariates, severity perception was associated with an increase in depressive symptoms, while pandemic control was negatively related to depressive symptoms. Regarding the impact of quarantine experiences, we found that home quarantine was associated with lower levels of depressive symptoms, while SARS quarantine experience was associated with increased levels of depressive symptoms. These findings suggest that in the short term, home quarantine could support mental health by reducing risk of infection, but in the long term, quarantine experiences may have a scarring effect on mental health.

Columns 1-4 of Table 3 report the estimated effects for the 25th, 50th, and 75th quantiles of the distribution of depressive symptoms. The $\mathrm{QR}$ estimates suggest that the mean effect derived from the OLS estimates masks considerable heterogeneities (see Fig. 4). While the impact of severity perception was significant in all three quantiles, the effect rises nearly monotonically from 0.547 in the 25 th quantile to 2.752 in the 75 th quantile, indicating that people with more depressive symptoms were more

Table 2 Intercorrelations among main variables of interest

\begin{tabular}{|c|c|c|c|c|c|c|c|c|}
\hline Variables & 1 & 2 & 3 & 4 & 5 & 6 & 7 & 8 \\
\hline Depressive symptoms & - & & & & & & & \\
\hline Happiness & $-0.32 * * *$ & - & & & & & & \\
\hline Severity perception & $0.17 * * *$ & $-0.11 * * *$ & - & & & & & \\
\hline Credibility of real-time data & $-0.08 * * *$ & $0.12 * * *$ & $-0.07 * * *$ & - & & & & \\
\hline Pandemic control & $-0.17 * * *$ & $0.18^{* * *}$ & $-0.12 * * *$ & $0.06^{* * *}$ & - & & & \\
\hline SARS quarantine experience & $0.06^{* * *}$ & -0.01 & 0.01 & 0.01 & 0.01 & - & & \\
\hline Community-level quarantine & 0.03 & -0.01 & -0.01 & -0.03 & $0.07 * * *$ & $0.10 * * *$ & - & \\
\hline Home quarantine & -0.00 & $0.05 * *$ & $-0.06 * *$ & 0.03 & 0.04 & 0.01 & $0.10 * * *$ & - \\
\hline
\end{tabular}

$* p<0.1, * * p<0.05, * * * p<0.01$ 
Table 3 The OLS and QR estimates (dependent variable: depressive symptoms)

\begin{tabular}{|c|c|c|c|c|}
\hline & (1) & (2) & (3) & (4) \\
\hline & OLS & 25 th & 50th & 75th \\
\hline Severity perception & $1.977 * * *(0.361)$ & $0.547 *(0.285)$ & $1.529 * * *(0.357)$ & $2.752 * * *(0.658)$ \\
\hline Credibility of real-time data & $-0.268(0.509)$ & $-0.168(0.311)$ & $-0.492(0.350)$ & $-1.459 *(0.749)$ \\
\hline Pandemic control & $\begin{array}{c}-2.565^{* * * *} \\
(0.706)\end{array}$ & $-0.776(0.741)$ & $-2.078 * *(0.884)$ & $\begin{array}{c}-3.084 * * * \\
(1.163)\end{array}$ \\
\hline $\begin{array}{l}\text { SARS quarantine } \\
\text { experience }\end{array}$ & $0.810 * *(0.385)$ & $0.479(0.315)$ & $1.197 * * *(0.399)$ & $0.780(0.701)$ \\
\hline $\begin{array}{l}\text { Community-level } \\
\text { quarantine }\end{array}$ & $0.690(0.656)$ & $0.452(0.450)$ & $0.204(0.510)$ & $0.914(1.238)$ \\
\hline Home quarantine & $-0.660 *(0.346)$ & $-0.517 * *(0.212)$ & $-0.806^{*}(0.418)$ & $-1.003 *(0.558)$ \\
\hline Gender & $-0.329(0.348)$ & $-0.459 *(0.274)$ & $-0.388(0.408)$ & $-0.791 *(0.466)$ \\
\hline Age & $0.008(0.027)$ & $0.014(0.026)$ & $-0.011(0.044)$ & $-0.006(0.040)$ \\
\hline Self-reported health & $\begin{array}{c}-3.243^{* * * *} \\
(0.392)\end{array}$ & $-1.825 * * *(0.44)$ & $\begin{array}{c}-3.389 * * * \\
(0.642)\end{array}$ & $\begin{array}{c}-4.643 * * * \\
(0.700)\end{array}$ \\
\hline Rural hukou & $0.223(0.400)$ & $0.247(0.224)$ & $0.075(0.373)$ & $0.482(0.617)$ \\
\hline Junior middle school & $1.684(1.668)$ & $-0.111(1.138)$ & $-1.163(2.456)$ & $0.789(2.841)$ \\
\hline Senior middle school & $1.487(1.581)$ & $0.786(1.213)$ & $-0.872(2.187)$ & $0.942(2.597)$ \\
\hline College or above & $1.848(1.550)$ & $1.069(1.193)$ & $-0.296(2.235)$ & $1.031(2.579)$ \\
\hline Poor family & $0.913 *(0.514)$ & $0.278(0.434)$ & $0.459(0.681)$ & $1.292(0.802)$ \\
\hline Married & $\begin{array}{c}-1.646^{* * * *} \\
(0.484)\end{array}$ & $-0.651(0.425)$ & $-1.507 * *(0.686)$ & $\begin{array}{c}-2.535 * * * \\
(0.920)\end{array}$ \\
\hline Religious believer & $0.688(0.637)$ & $0.501(0.478)$ & $0.119(0.784)$ & $0.306(0.843)$ \\
\hline COVID-19 cases & $1.375(1.512)$ & $1.305(1.921)$ & $0.905(1.513)$ & $3.764(3.204)$ \\
\hline Food/water shortage & $3.026 * * *(0.656)$ & $2.379 * *(1.073)$ & $4.038 * * *(0.730)$ & $2.896^{* * *}(0.889)$ \\
\hline Family contacts & $0.439(0.351)$ & $0.351(0.298)$ & $0.550(0.411)$ & $0.802(0.361)$ \\
\hline Perceived fairness & $\begin{array}{c}-1.571 * * * \\
(0.348)\end{array}$ & $\begin{array}{c}-0.809 * * * \\
(0.235)\end{array}$ & $\begin{array}{c}-2.171 * * * \\
(0.487)\end{array}$ & $\begin{array}{c}-2.239 * * * \\
(0.768)\end{array}$ \\
\hline Generalized trust & $-0.642 *(0.372)$ & $-0.466(0.308)$ & $-0.511(0.498)$ & $-1.205(0.944)$ \\
\hline Constant & $18.737 * * *(2.209)$ & $11.034 * * *(1.668)$ & $19.583 * * *(2.989)$ & $25.593 * * *(3.392)$ \\
\hline Provincial dummies & Yes & Yes & Yes & Yes \\
\hline Observations & 1847 & 1847 & 1847 & 1847 \\
\hline
\end{tabular}

$* p<0.1, * * p<0.05, * * * p$ value $<0.01$

strongly affected by their perception of COVID-19 severity. Although the impact of real-time data credibility is not significant in the OLS estimation, quantile regression analysis showed an effect in the 75th quantile. Conversely, while the effect of pandemic control was significant in the OLS estimation, the quantile examination revealed significant effects only in the quantiles of 0.50 th and 0.75 th $(-2.078$ versus -3.084$)$. Overall, these results indicate that conditional on other covariates, those in the upper end of the distribution of depression scores benefit more from having favorable attitudes towards COVID-19. Similarly, the beneficial impact of home quarantine on reducing depression is stronger for people in the upper end of the distribution of depression scores. 

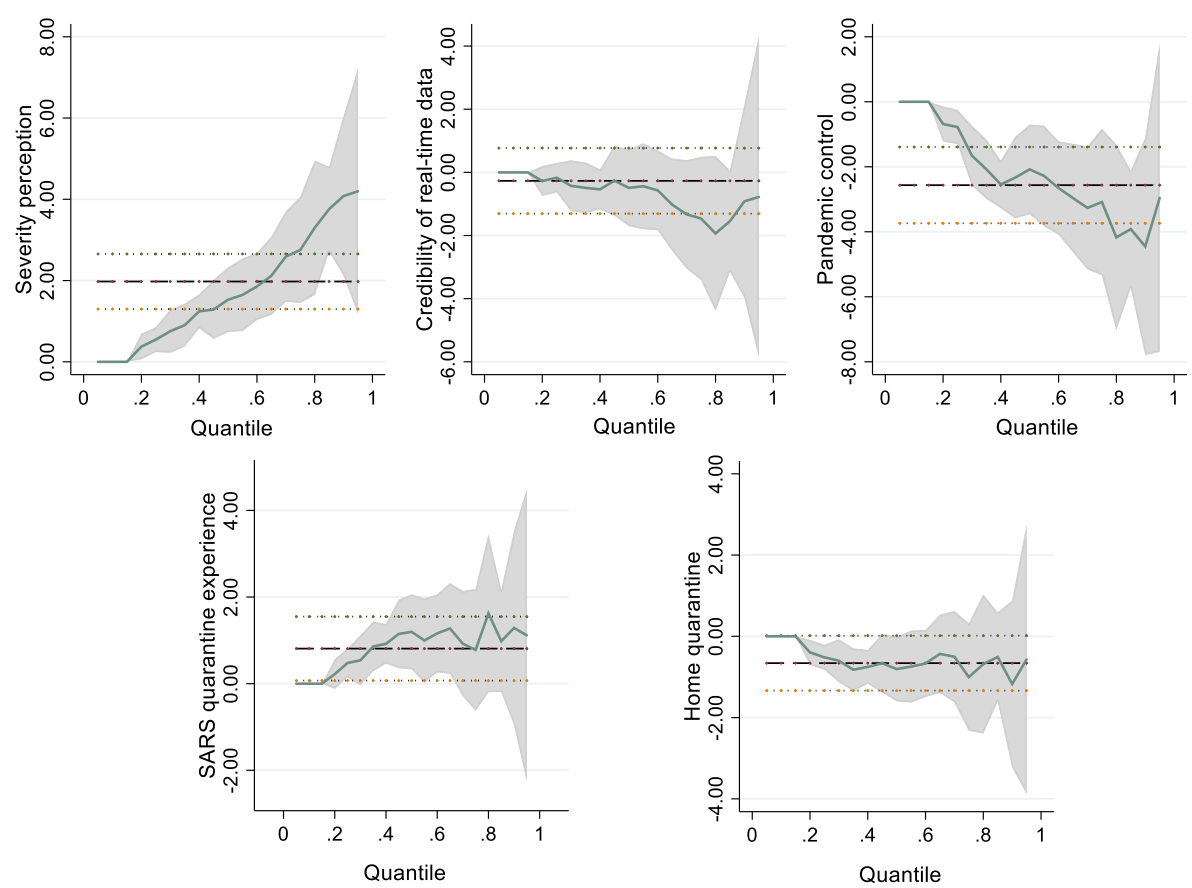

Fig. 4 Distributional effects on depressive symptoms

We next examined the impact of quarantine and attitudes towards COVID-19 on happiness (Table 4). In column 1, we found that severity perception was negatively related to happiness, while credibility of real-time data and pandemic control were positively related to happiness, underscoring the importance of favorable attitudes in promoting mental health. Additionally, while home quarantine was positively associated with happiness, community-level quarantine was negatively related to happiness.

Columns 2-4 of Table 4 report the coefficients for QR estimates predicting happiness. Figure 5 provides additional details on these results by plotting the heterogeneous impacts of quarantine and attitudinal metrics. Three main findings are worth noting: First, the happiness of people at the lower end of the distribution of happiness scores was more affected by their perceptions of pandemic severity, while those with higher levels of happiness were more affected by their attitude to pandemic control. Second, the impact of community-level quarantine varies widely across the happiness distribution, changing from -0.346 in the 25 th quantile to 0.022 in the 75 th quantile, and was only significant at lower quantiles. Third, the effect of home quarantine was not significant at the bottom end of the happiness distribution, but was positive and significant at the median and upper parts of the distribution $(50$ th $=0.159 ; 75$ th $=0.255)$. This finding suggests that happier people care more about the risk of infection and therefore benefit more from home quarantine.

Finally, the examination of other covariates on depressive symptoms and happiness revealed two key findings: First, having close family contacts was positively related to happiness. Second, perceived fairness and generalized trust were positively related to happiness and negatively related to depression. 
Table 4 The OLS and QR estimates (dependent variable: happiness)

\begin{tabular}{|c|c|c|c|c|}
\hline & (1) & (2) & (3) & (4) \\
\hline & OLS & 25 th & 50 th & 75th \\
\hline Severity perception & $-0.146^{*}(0.081)$ & $\begin{array}{r}-0.246 * * \\
(0.121)\end{array}$ & $-0.227 * *(0.093)$ & $0.001(0.140)$ \\
\hline Credibility of real-time data & $0.275^{* *}(0.124)$ & $0.290 * *(0.148)$ & $0.498 * *(0.193)$ & $0.361 * *(0.181)$ \\
\hline Pandemic control & $0.571 * * *(0.160)$ & $0.396(0.279)$ & $0.545 * *(0.234)$ & $0.493 * *(0.196)$ \\
\hline $\begin{array}{l}\text { SARS quarantine } \\
\text { experience }\end{array}$ & $0.039(0.090)$ & $0.091(0.158)$ & $-0.095(0.116)$ & $0.110(0.112)$ \\
\hline $\begin{array}{l}\text { Community-level } \\
\text { quarantine }\end{array}$ & $-0.266 * *(0.134)$ & $\begin{array}{r}-0.346^{* *} \\
(0.176)\end{array}$ & $-0.214(0.183)$ & $-0.022(0.188)$ \\
\hline Home quarantine & $0.160 *(0.083)$ & $0.028(0.120)$ & $0.159 * *(0.071)$ & $0.255^{* * *}(0.096)$ \\
\hline Gender & $-0.173 * *(0.082)$ & $-0.149(0.126)$ & $-0.123(0.118)$ & $-0.172(0.114)$ \\
\hline Age & $-0.019 * *(0.007)$ & $-0.018 *(0.010)$ & $\begin{array}{c}-0.029 * * * \\
(0.010)\end{array}$ & $\begin{array}{r}-0.021 * * \\
(0.008)\end{array}$ \\
\hline Self-reported health & $0.824 * * *(0.092)$ & $0.969 * * *(0.091)$ & $0.933 * * *(0.126)$ & $0.807 * * *(0.112)$ \\
\hline Rural hukou & $-0.211 * *(0.090)$ & $-0.278 *(0.158)$ & $-0.297 * *(0.132)$ & $-0.136(0.107)$ \\
\hline Junior middle school & $0.415(0.580)$ & $0.000(0.794)$ & $0.603(0.635)$ & $0.386(0.912)$ \\
\hline Senior middle school & $-0.079(0.580)$ & $-0.363(0.677)$ & $-0.014(0.656)$ & $-0.105(0.837)$ \\
\hline College or above & $-0.090(0.571)$ & $0.054(0.663)$ & $-0.001(0.549)$ & $-0.491(0.837)$ \\
\hline Poor family & $\begin{array}{c}-0.397 * * * \\
(0.125)\end{array}$ & $-0.319 *(0.176)$ & $-0.360 *(0.187)$ & $-0.145(0.147)$ \\
\hline Married & $0.300 * * *(0.113)$ & $0.299 *(0.168)$ & $0.454 * * *(0.129)$ & $0.507 * * *(0.108)$ \\
\hline Religious believer & $0.117(0.158)$ & $-0.081(0.242)$ & $0.242(0.226)$ & $0.339 *(0.201)$ \\
\hline COVID-19 cases & $0.326(0.260)$ & $0.187(0.351)$ & $0.228(0.389)$ & $0.431(0.451)$ \\
\hline Food/water shortage & $-0.241 *(0.140)$ & $\begin{array}{r}-0.449 * * \\
(0.220)\end{array}$ & $-0.278(0.199)$ & $-0.057(0.130)$ \\
\hline Family contacts & $0.310 * * *(0.080)$ & $0.245^{*}(0.144)$ & $0.314 * * *(0.094)$ & $0.206 *(0.126)$ \\
\hline Perceived fairness & $0.410 * * *(0.082)$ & $0.444 * *(0.174)$ & $0.431 * * *(0.096)$ & $0.313 * *(0.150)$ \\
\hline Generalized trust & $0.503 * * *(0.085)$ & $0.638 * * *(0.104)$ & $0.409 * * *(0.106)$ & $0.416 * * *(0.142)$ \\
\hline Constant & $6.823 * * *(0.691)$ & $5.956 * * *(1.022)$ & $7.260 * * *(0.779)$ & $8.238 * * *(0.985)$ \\
\hline Provincial dummies & Yes & Yes & Yes & Yes \\
\hline Observations & 1849 & 1849 & 1849 & 1849 \\
\hline
\end{tabular}

$* p<0.1, * * p<0.05, * * * p$ value $<0.01$

\section{Discussion}

\section{Summary of Key Findings}

In this paper, we explore how mental health is related to quarantine experiences and attitudes towards COVID-19 in China. We have provided a unique examination of the heterogeneity of these relationships across the distributions of depressive symptoms and happiness. As far as we are aware, ours is the first paper to examine how the impact of quarantine experiences and attitudes towards COVID-19 on mental health changes across the distribution of mental health measures. 

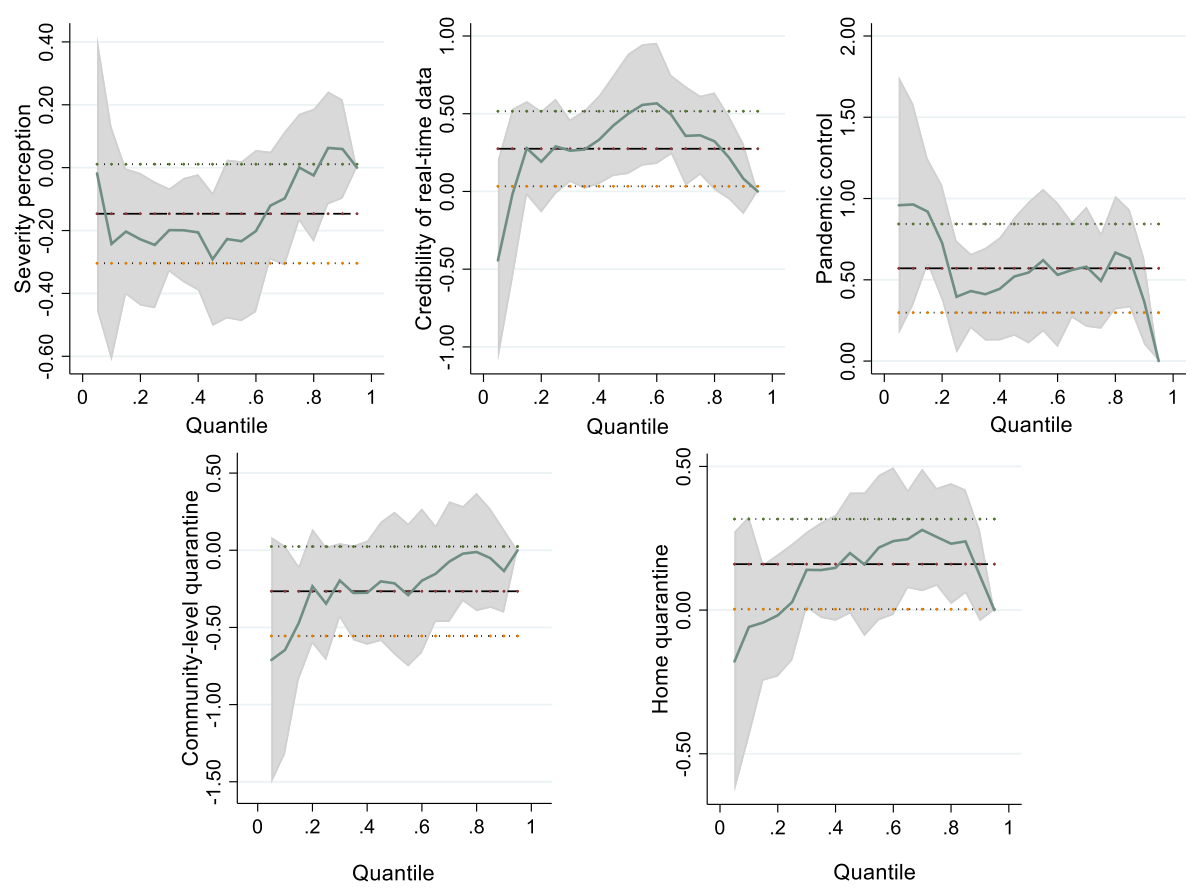

Fig. 5 Distributional effects on happiness

Our findings support two main conclusions: First, favorable attitudes towards COVID-19 (including reduced severity perception, belief in the credibility of realtime updates, and increased confidence in pandemic control) are associated with reduced depressive symptoms and increased happiness. Our quantile regression analysis further demonstrated that although people with more depressive symptoms or lower levels of happiness are more affected by their beliefs about COVID-19 severity, those with milder depression or higher levels of happiness are more affected by the credibility of real-time updates and the pandemic control.

Second, we demonstrated that home quarantine during the COVID-19 pandemic is associated with decreased depressive symptoms and increased happiness, presumably because home quarantine reduces the risk of infection. Conversely, community-level quarantine has deleterious psychological impacts. This may be because communitylevel quarantine implies that local outbreak is severe or out of control, possibly fostering a climate of panic and feeling coerced. Additionally, community-level quarantine impacts people's daily life more than home quarantine. Finally, home quarantine is more likely to be a rational choice for self-protection, which can reduce the fear of infection and thus help increase happiness.

It is also worth noting that our results underscored the importance of family support, perceived fairness, and generalized trust during the COVID-19 pandemic. Indeed, the seminal work by Shek and his collaborators has consistently emphasized the vital role of family support and relationships in affecting psychological outcomes in the Chinese context (e.g., Leung and Shek 2020; Shek 1998, 2005, 2008). For example, recent work by Shek et al. (2019) has shown that better parental-child relationship can help reduce the initial level of Internet addiction among Chinese adolescents. One possible 
explanation for the beneficial role of perceived fairness and generalized trust is that people living in a society with high levels of fairness and trust may have a strong sense of belonging (Knack and Keefer 1997), thereby leading to greater social cohesion and cooperation (Alesina et al. 2004), all of which may help them overcome the difficulties during the pandemic.

\section{Policy Implications}

Overall, our findings have important implications for improving the mental health of the public, especially during the COVID-19 pandemic: First, as Brooks et al. (2020) posited, quarantine can have lasting, widespread, and substantial psychological effects. Successful containment measures should take the psychological costs of quarantine into account. In response to public mental health concerns in China, the National Health Commission of China (2020) has issued guidelines to local authorities to promote psychological crisis intervention related to the COVID-19 outbreak. Additionally, many psychological counseling centers have set up special hotlines to provide psychological counseling services to those in need (Bao et al. 2020). Undoubtedly, these measures play a role in alleviating public psychological pressure. However, for a country like China, where social mobilization is easy to achieve and often effective, more detailed assessments of the impacts of macro-level segregation are needed because restricting the activities of individuals may not only cause inconveniences and be detrimental to the economy, but can have negative impacts on mental health.

Second, the rapid and real-time dissemination of authoritative pandemic information is crucial to alleviating negative public sentiment. A lack of authoritative information could lead the public to ignore the epidemic, exacerbating the outbreak and increasing follow-up costs (Gong et al. 2020). As Harari (2020) has recently emphasized: "A self-motivated and well-informed population is usually far more powerful and effective than a policed, ignorant population." In addition, given the importance of social cohesion and trust, close cooperation among governments at all levels should be strengthened to reduce stigma and employment discrimination against migrants resulting from quarantine or lockdown.

\section{Limitations and Future Research Directions}

Several limitations of this paper warrant discussion. First, while quantile regression allows us to capture the heterogeneous associations between explanatory variables and mental health, we employed a cross-sectional design, making it difficult to rule out potential endogeneity issues (especially reverse causality) and determine the causal impact of quarantine experiences and attitudes towards COVID-19 on mental health. For example, although it is unlikely that depressive symptoms or happiness will affect the status of community-level quarantine, people in good mental health could be more likely to remain optimistic and choose to be home quarantined during a pandemic, thereby leading to the issue of reverse causality. This possibility is partially supported by Sun and Shek (2010) and Diener and Chan (2011). The former study found that adolescents with higher levels of subjective well-being were less likely to have problem behaviors, while the latter argued that good mental health was related to protective psychosocial and behavioral metrics such as optimism, adaptive coping responses, and healthy behaviors. 
Second, although we were able to tap into the long-term impact of quarantine by using SARS quarantine experience as a predictor of current mental health, our examination of the scarring effect of the SARS quarantine experience is preliminary and does not necessarily indicate a long-term impact of COVID-19 quarantine, given the different characteristics of these epidemic outbreaks. For instance, individuals may be more tolerant of quarantine or isolation during the COVID-19 than the SARS outbreak, because the rapid development of the Internet and online communication has facilitated social connections and also provided new forms of entertainment during the current pandemic. As a final limitation, while we believe that Internet surveys have the advantage over face-to-face surveys of being conducted in private, which may help reduce social desirability biases, our mobile Internet-based survey may generate skewed data due to sample selection issues (Heckman 1979). In particular, our respondents may over-represent the views of young netizens and well-educated groups, limiting the generalizability of our findings.

Despite these limitations, our work is among the first to provide a glimpse into the psychological impact of the COVID-19 pandemic. Future studies can enrich and expand this research by using longitudinal or experimental research designs to establish causal links between quarantine experiences and mental health. In particular, fixed effects quantile regression based on longitudinal data would be an appropriate tool to test the relationship between quarantine and mental health: by eliminating fixed effects that are constant over time, different individuals could be "homogenized" and thus more comparable (Binder and Coad 2011). Moreover, exploring the moderating role of societal attitudes (e.g., social and institutional trust, fairness perception, and perceived discrimination) and the mediating role of channel variables (e.g., financial burden and social stigma) may deepen our understanding of how quarantine affects mental health.

\section{Conclusions}

The outbreak of COVID-19 poses a major challenge to the normal functioning of societies and human health. Despite ample evidence on the psychological consequences of quarantine, virtually, no empirical studies have explored this topic in the context of the COVID-19 pandemic. Moreover, little is known about how attitudes towards the epidemics affect mental health. The present study suggests that homebased quarantine and optimistic attitudes are associated with decreased depression and increased happiness, and that this relationship varies across the distribution of mental health scores. In the future, research designs that allow for causal inference and mediation analysis will help specify the impact of quarantine on mental health.

Acknowledgments This study was funded by the National Natural Science Foundation of China (grant numbers: 71603052; 71804142) and the Social Science Foundation in Jiangsu Province (grant number: No. 19EYD009).

Authors' Contributions H. Y. Lu conceived of the study, participated in its design and coordination, performed the statistical analyses, and drafted the manuscript; P. Nie and L. Qian participated in the design and helped to draft and revise the manuscript. All authors read and approved the final manuscript. 


\section{Compliance with Ethical Standards}

Conflict of Interest The authors declare that they have no conflict of interest.

Ethical Approval Not applicable.

Informed Consent Informed consents were obtained from all respondents included in the study.

\section{References}

Aghababaei, N., Sohrabi, F., Eskandari, H., Borjali, A., Farrokhi, N., \& Chen, Z. J. (2016). Predicting subjective well-being by religious and scientific attitudes with hope, purpose in life, and death anxiety as mediators. Personality and Individual Differences, 90, 93-98.

Alesina, A., Di Tella, R., \& MacCulloch, R. (2004). Inequality and happiness: are Europeans and Americans different? Journal of Public Economics, 88(9), 2009-2042.

Arampatzi, E., Burger, M. J., \& Novik, N. (2018). Social network sites, individual social capital and happiness. Journal of Happiness Studies, 19(1), 99-122.

Ayers, B., Forshaw, M., \& Hunter, M. S. (2010). The impact of attitudes towards the menopause on women's symptom experience: a systematic review. Maturitas, 65(1), 28-36.

Bao, Y., Sun, Y., Meng, S., Shi, J., \& Lu, L. (2020). 2019-nCoV epidemic: address mental health care to empower society. The Lancet., 395, e37-e38. https://doi.org/10.1016/S0140-6736(20)30309-3.

Barbisch, D., Koenig, K. L., \& Shih, F. (2015). Is there a case for quarantine? Perspectives from SARS to Ebola. Disaster Medicine and Public Health Preparedness, 9(5), 547-553.

Binder, M., \& Coad, A. (2011). From average Joe's happiness to miserable Jane and cheerful John: using quantile regressions to analyze the full subjective well-being distribution. Journal of Economic Behavior \& Organization, 79(3), 275-290.

Boey, K. W. (1999). Cross-validation of a short form of the CES-D in Chinese elderly. International Journal of Geriatric Psychiatry, 14(8), 608-617.

Boyes, A., Newell, S., Girgis, A., McElduff, P., \& Sanson-fisher, R. (2006). Does routine assessment and realtime feedback improve cancer patients' psychosocial well-being? European Journal of Cancer Care, 15(2), 163-171.

Brooks, S. K., Webster, R. K., Smith, L. E., Woodland, L., Wessely, S., Greenberg, N., \& Rubin, G. J. (2020). The psychological impact of quarantine and how to reduce it: rapid review of the evidence. The Lancet., 395, 912-920. https://doi.org/10.1016/S0140-6736(20)30460-8.

Callus, E., Utens, E. M. W. J., Quadri, E., Ricci, C., Carminati, M., Giamberti, A., \& Chessa, M. (2014). The impact of actual and perceived disease severity on pre-operative psychological well-being and illness behaviour in adult congenital heart disease patients. Cardiology in the Young, 24(2), 275-282.

Chen, S., Zhang, Z., Yang, J., Wang, J., Zhai, X., Bärnighausen, T., \& Wang, C. (2020). Fangcang shelter hospitals: a novel concept for responding to public health emergencies. The Lancet., 395, 1305-1314. https://doi.org/10.1016/S0140-6736(20)30744-3.

Cheung, Y. B., Liu, K. Y., \& Yip, P. S. F. (2007). Performance of the CES-D and its short forms in screening suicidality and hopelessness in the community. Suicide and Life-threatening Behavior, 37(1), 79-88.

Chong, M., Wang, W., Hsieh, W., Lee, C., Chiu, N., Yeh, W., et al. (2004). Psychological impact of severe acute respiratory syndrome on health workers in a tertiary hospital. The British Journal of Psychiatry, 185(2), 127-133.

Diener, E., \& Chan, M. Y. (2011). Happy people live longer: subjective well-being contributes to health and longevity. Applied Psychology: Health and Well-Being, 3(1), 1-43.

DiGiovanni, C., Conley, J., Chiu, D., \& Zaborski, J. (2004). Factors influencing compliance with quarantine in Toronto during the 2003 SARS outbreak. Biosecurity and Bioterrorism: Biodefense Strategy, Practice, and Science, 2(4), 265-272.

Gong, B., Zhang, S., Yuan, L., \& Chen, K. Z. (2020). A balance act: minimizing economic loss while controlling novel coronavirus pneumonia. Journal of Chinese Governance., 5, 249-268. https://doi. org/10.1080/23812346.2020.1741940. 
Halvorsen, M., Wang, C. E., Eisemann, M., \& Waterloo, K. (2010). Dysfunctional attitudes and early maladaptive schemas as predictors of depression: a 9-year follow-up study. Cognitive Therapy and Research, 34(4), 368-379.

Harari, Y. N. (2020). The world after coronavirus. Financial Times, March 20. https://www.ft.com/content/19 d90308-6858-11ea-a3c9-1fe6fedcca 75.

Heckman, J. J. (1979). Sample selection bias as a specification error. Econometrica, 47(1), 153-161.

Iyer, R., \& Muncy, J. A. (2016). Attitude toward consumption and subjective well-being. Journal of Consumer Affairs, 50(1), 48-67.

Jalloh, M. F., Li, W., Bunnell, R. E., Ethier, K. A., O Leary, A., Hageman, K. M., et al. (2018). Impact of Ebola experiences and risk perceptions on mental health in Sierra Leone, July 2015. BMJ Global Health, 3(2), e000471. https://doi.org/10.1136/bmjgh-2017-000471.

Jeong, H., Yim, H. W., Song, Y., Ki, M., Min, J., Cho, J., et al. (2016). Mental health status of people isolated due to Middle East Respiratory Syndrome. Epidemiology and Health, 38. https://doi.org/10.4178/epih. e2016048.

Kang, L., Li, Y., Hu, S., Chen, M., Yang, C., Yang, B. X., Wang, Y., Hu, J., Lai, J., Ma, X., Chen, J., Guan, L., Wang, G., Ma, H., \& Liu, Z. (2020). The mental health of medical workers in Wuhan, China dealing with the 2019 novel coronavirus. The Lancet Psychiatry, 7(3), e14. https://doi.org/10.1016/S2215-0366 (20)30047-X.

Karamouzian, M., \& Hategekimana, C. (2015). Ebola treatment and prevention are not the only battles: understanding Ebola-related fear and stigma. International Journal of Health Policy and Management, $4(1), 55-56$.

Kato, K., Zweig, R., Schechter, C. B., Barzilai, N., \& Atzmon, G. (2016). Positive attitude toward life, emotional expression, self-rated health, and depressive symptoms among centenarians and near-centenarians. Aging \& Mental Health, 20(9), 930-939.

Knack, S., \& Keefer, P. (1997). Does social capital have an economic payoff? A cross-country investigation. The Quarterly Journal of Economics, 112(4), 1251-1288.

Koenker, R., \& Bassett, J. G. (1978). Regression quantiles. Econometrica, 46(1), 33-50.

Lee, S. M., Kang, W. S., Cho, A., Kim, T., \& Park, J. K. (2018). Psychological impact of the 2015 MERS outbreak on hospital workers and quarantined hemodialysis patients. Comprehensive Psychiatry, 87, 123127.

Leung, J. T. Y., \& Shek, D. T. L. (2020). Parental control and adolescent wellbeing in Chinese adolescents in Hong Kong. Child Indicators Research, 13(2), 703-727.

Lin, E. C. L., Peng, Y. C., \& Hung Tsai, J. C. (2010). Lessons learned from the anti-SARS quarantine experience in a hospital-based fever screening station in Taiwan. American Journal of Infection Control, 38(4), 302-307.

Liu, S., Yang, L., Zhang, C., Xiang, Y., Liu, Z., Hu, S., et al. (2020). Online mental health services in China during the COVID-19 outbreak. The Lancet Psychiatry, 7(4), e17-e18. https://doi.org/10.1016/S22150366(20)30077-8.

Locke, B., Low, M., \& Forsgren, E. (2019). An integrated management strategy to prevent outbreaks and eliminate infection pressure of American foulbrood disease in a commercial beekeeping operation. Preventive Veterinary Medicine, 167, 48-52.

Ma, C. M. S., Shek, D. T. L., \& Chen, J. M. T. (2019). Changes in the participants in a community-based positive youth development program in Hong Kong: objective outcome evaluation using a one-group pretest-posttest design. Applied Research in Quality of Life, 14(4), 961-979.

Maynard, M. S., Perlman, C. M., \& Kirkpatrick, S. I. (2019). Food insecurity and perceived anxiety among adolescents: an analysis of data from the 2009-2010 National Health and Nutrition Examination Survey (NHANES). Journal of Hunger \& Environmental Nutrition, 14(3), 339-351.

Morgan, K., Villiers-Tuthill, A., Barker, M., \& McGee, H. (2014). The contribution of illness perception to psychological distress in heart failure patients. BMC Psychology, 2(1), 50-e18. https://doi.org/10.1186 /s40359-014-0050-3.

Moss Morris, R., Petrie, K. J., \& Weinman, J. (1996). Functioning in chronic fatigue syndrome: do illness perceptions play a regulatory role? British Journal of Health Psychology, 1(1), 15-25.

National Health Commission of China. (2020). Guideline for psychological crisis intervention during the outbreak of COVID-19 (in Chinese). Accessed January 17, 2020. http://www.nhc.gov.cn/jkj/s3577 /202001/6adc08b966594253b2b791be5c3b9467.shtml

Radloff, L. S. (1977). The CES-D scale: a self-report depression scale for research in the general population. Applied Psychological Measurement, 1(3), 385-401. 
Reynolds, D. L., Garay, J. R., Deamond, S. L., Moran, M. K., Gold, W., \& Styra, R. (2008). Understanding, compliance and psychological impact of the SARS quarantine experience. Epidemiology \& Infection, 136(7), 997-1007.

Robertson, E., Hershenfield, K., Grace, S. L., \& Stewart, D. E. (2004). The psychosocial effects of being quarantined following exposure to SARS: a qualitative study of Toronto health care workers. The Canadian Journal of Psychiatry, 49(6), 403-407.

Shallcross, A. J., Troy, A. S., Boland, M., \& Mauss, I. B. (2010). Let it be: accepting negative emotional experiences predicts decreased negative affect and depressive symptoms. Behaviour Research and Therapy, 48(9), 921-929.

Shek, D. T. L. (1990). Reliability and factorial structure of the Chinese version of the Beck Depression Inventory. Journal of Clinical Psychology, 46(1), 35-43.

Shek, D. T. L. (1998). A longitudinal study of the relations between parent-adolescent conflict and adolescent psychological well-being. The Journal of Genetic Psychology, 159(1), 53-67.

Shek, D. T. L. (2005). Paternal and maternal influences on the psychological well-being, substance abuse, and delinquency of Chinese adolescents experiencing economic disadvantage. Journal of Clinical Psychology, 61(3), 219-234.

Shek, D. T. L. (2008). Perceived parental control and parent-child relational qualities in early adolescents in Hong Kong: parent gender, child gender and grade differences. Sex Roles, 58(9-10), 666-681.

Shek, D. T. L. (2014). Applied research in quality of life (ARQOL): where are we and issues for consideration. Applied Research in Quality of Life, 9(3), 465-468.

Shek, D. T. L., Zhu, X., \& Dou, D. (2019). Influence of family processes on Internet addiction among late adolescents in Hong Kong. Frontiers in Psychiatry, 10. https://doi.org/10.3389/fpsyt.2019.00113.

Shrout, P. E., \& Yager, T. J. (1989). Reliability and validity of screening scales: effect of reducing scale length. Journal of Clinical Epidemiology, 42(1), 69-78.

Sprang, G., \& Silman, M. (2013). Posttraumatic stress disorder in parents and youth after health-related disasters. Disaster Medicine and Public Health Preparedness, 7(1), 105-110.

Sun, R. C. F., \& Shek, D. T. L. (2010). Life satisfaction, positive youth development, and problem behaviour among Chinese adolescents in Hong Kong. Social Indicators Research, 95(3), 455-474.

Taylor, M. R., Agho, K. E., Stevens, G. J., \& Raphael, B. (2008). Factors influencing psychological distress during a disease epidemic: data from Australia's first outbreak of equine influenza. BMC Public Health, 8(1), 347-e18. https://doi.org/10.1186/1471-2458-8-347.

World Health Organization. (2020). Coronavirus disease (COVID-19) situation dashboard. Accessed May 25, 2020. https://covid19.who.int/

Xiang, Y., Yang, Y., Li, W., Zhang, L., Zhang, Q., Cheung, T., et al. (2020). Timely mental health care for the 2019 novel coronavirus outbreak is urgently needed. The Lancet Psychiatry, 7(3), 228-229.

Xu, J., Wu, Z., Schimmele, C. M., \& Li, S. (2019). Widowhood and depression: a longitudinal study of older persons in rural China. Aging \& Mental Health. https://doi.org/10.1080/13607863.2019.1571016.

Zhang, B., Yan, X., Zhao, F., \& Yuan, F. (2015). The relationship between perceived stress and adolescent depression: the roles of social support and gender. Social Indicators Research, 123(2), 501-518.

Zhang, M., Hong, L., Zhang, T., Lin, Y., Zheng, S., Zhou, X., et al. (2016). Illness perceptions and stress: mediators between disease severity and psychological well-being and quality of life among patients with Crohn's disease. Patient Preference and Adherence, 10, 2387-2e18. https://doi.org/10.2147/PPA. S118413.

Publisher's Note Springer Nature remains neutral with regard to jurisdictional claims in published maps and institutional affiliations. 